\title{
Las infografías como herramienta de transferencia social
}

\section{María Ángeles Carabal Montagud, José Manuel Taroncher Ballesterob ${ }^{b}$ Virginia Santamarina Campos ${ }^{c}$, María Victoria Esgueva López ${ }^{\mathrm{d}}$}

${ }^{\mathrm{a}}$ Universitat Politècnica de València, València, Spain, macamon@crbc.upv.es, ${ }^{\mathrm{b}}$ Generalitat Valenciana, València, Spain, taroncher_jos@gva.es ' Universitat Politècnica de València, València, Spain, virsanca@crbc.upv.es ${ }^{\mathrm{d}}$ Universitat Politècnica de València, València, Spain, maeslo2@dib.upv.es

\section{Resumen}

El uso de infografías facilita la comprensión de problemáticas complejas, con relativa sencillez. Adoptar su uso en el ámbito universitario, puede ayudar al alumnado a sintetizar y estructurar los contenidos en claves visuales, adaptadas a sus códigos de interpretación, además de fomentar la creatividad en la presentación de los resultados de investigación.

Con ello, el alumnado debe, no solo aprehender los contenidos trabajados, ahondar en ellos para extraer conceptos clave, sino además trabajar la competencia tecnológica desde un punto de vista creativo, innovador, visual y dinámico.

En la transferencia social de la investigación, que se genera en la universidad, supone un reto presentar estos contenidos, desde un punto de vista conceptual, de rápida lectura y comprensión y además, que resulten atractivos al receptor de la información. En este contexto, con el empleo de la metodología de Aprendizaje-Servicio, las competencias adquiridas por el alumnado, deben quedar patentes, generando contenidos de fácil comprensión para el público en general, sin vinculación al ámbito universitario.

La transferencia social de los resultados obtenidos es es el último eslabón que completa el aprendizaje, dimensiona su investigación en el contexto comunitario y lo integra en la cotidianidad.

Palabras clave: Infografias; TIC; Creatividad; Innovación; Docencia; Aprendizaje-Servicio; Transferencia Social 


\section{Introducción}

\subsection{Contexto de la investigación}

El contexto del presente artículo es la unión de las experiencias de docentes respecto a la transferencia de la información a la sociedad, de los trabajos universitarios, que en ocasiones prestan un servicio social, utilizando la metodología de Aprendizaje-Servicio, en el caso de la conservación y restauración de bienes culturales.

El alumnado adquiere una serie de competencias y desarrolla sus competencias transversales, a lo largo de sus estudios, pero con la herramienta del aprendizaje servicio acaba de comprender la finalidad social de su trabajo.

En ocasiones los conceptos son complejos para la transmisión social, pero cuando se trata de intervenciones sobre el patrimonio, como es el caso de estudio, las herramientas tecnológicas pueden ayudar a transferir los conocimientos de manera sencilla, conceptual y muy visual, adaptándose así a los códigos visuales actuales.

Con ello, alcanzamos un doble objetivo, por un lado formar al alumnado en tareas sociales vinculadas con su futuro laboral, además de fomentar la adquisición y conceptualización de contenidos complejos, fomentando la aplicación de la tecnología y por otro lado, fomentamos un servicio a la sociedad, que en este caso no precisará de un esfuerzo, para comprender los resultados de las investigaciones que se pretenden transferir.

\section{2. Ámbito de estudio}

El ámbito de aplicación de la presente investigación en docencia es en el EICE titulado El proceso de Enseñanza y Aprendizaje Fuera de las Aulas de la Facultad de Bellas Artes: Baños de Realidad. Consideramos imprescindible para la formación holística del alumnado encontrar otros contextos de formación, que vayan más allá de lo que es el entorno universitario, y más concretamente a la hora de formar profesionales.

La presente investigación se centra en la experiencia desarrollada en el Grado en Conservación y Restauración de Bienes Culturales y en el Master Oficial en Conservación y Restauración de Bienes Culturales, de la Universitat Politécnica de València.

En este caso, la transferencia social se convierte en una de nuestras metas, dado que la conservación y restauración de bienes culturales ofrece un servicio social, siendo los encargados de la salvaguarda del patrimonio y en ocasiones, fuera de los museos, se queda reflejado en un documento que no traspasa las fronteras de lo privado, siendo nuestro 
objetivo dar visibilidad a nuestra tarea y dotar al alumnado de competencias generales y específicas, y competencias transversales de las que harán uso durante su vida laboral.

\section{Infografía enfocada a la transferencia social como herramienta del Aprendizaje-Servicio}

\subsection{Posibles áreas de aplicación}

El profesorado, en cada curso, realiza una serie de labores, impartiendo sus materias, aprobadas dentro de su Plan de Ordenación Docente -POD-, al tiempo que realiza su labor investigadora. El crisol de ambas áreas suele ser la dirección de Trabajos Final de Grado TFG- y Trabajos Final de Máster -TFM-, que aúnan ambos planos y generando trabajos, con orientación profesionalizadora, que en ocasiones son documentos que ofrecen un servicio social, y si se transfiriesen y divulgasen entre los actores implicados, constituirían documentos útiles en el plano real.

El trasvase de contenidos o de resultados de investigación suele ser una tarea compleja, dado que se mueven en la esfera universitaria y, en ocasiones emplea un lenguaje que no resulta de fácil comprensión por parte del público en general.

Para ello, el profesorado, no solamente tiene que presentar sus contenidos, sino ampliar estos, mediante el uso de la competencia tecnológica, con el fin de formar al alumnado para generar documentos que podrían resultar útiles a la sociedad.

\subsection{La importancia de la transferencia social en conservación restauración de patrimonio, dentro del Aprendizaje-Servicio}

La transferencia social en conservación y restauración tiene múltiples dimensiones. Algunas de ellas están vinculadas con poner en valor la investigación llevada cabo, sobre una determinada obra o conjunto, ya que en patrimonio es una de las vías para su conservación.

Además de la difusión relacionada con su historia, iconografía o función social en el pasado, otra de las cuestiones básicas que debe tener en cuenta el conservador y restaurador de bienes culturales, es plantear una serie de parámetros óptimos para la conservación preventiva, bien sea de obras que han sido intervenidas, o bien sea de obras que pretenden conservarse, estableciendo los medios óptimos para conseguirlo, como son la iluminación, la humedad relativa o la temperatura. Asimismo, cuestiones básicas serán también el mantenimiento, cuidado, limpieza periódica y manipulación -en caso de ser imagen 
procesional-. En este sentido, la vertiente profesionalizadora de los TFG y TFM que realizan, tiende a plantear estas cuestiones como parte de la metodología de AprendizajeServicio que desarrollan.

En ocasiones todos estos conceptos, resultan de difícil aplicación real, porque a la hora de transferirlos a la comunidad o colectivo a la que pertenece dicho patrimonio, no se alcanza un lenguaje que sea útil en ambos sentidos. Con ello, una de las labores de los TFG y TFM en conservación y restauración de bienes culturales, está vinculada con propuestas de catalogación, de intervención, de restauración y de conservación preventiva. En la presente investigación se ha ahondado en la posibilidad del empleo de la infografía dentro de la metodología Aprendizaje-Servicio, que consiste en aprender mientras se genera un contenido que sirve al conjunto de la sociedad, o a determinados grupos.

\subsection{Posibilidades de la infografía, como herramienta para la competencia tecnológica}

En la búsqueda de ese plano social deberíamos buscar idiomas cotidianos, que pudiesen encerrar mensajes complejos, dándoles una estética muy didáctica, innovadora y de fácil comprensión. La infografía se presenta como una herramienta muy visual, atractiva, didáctica, dinámica, de fácil visualización y con una gran utilidad, porque encierra contenidos complejos, en diagramas que siguen los códigos visuales sociales en la actualidad y pueden dar un servicio aplicable a muchas diciplinas, si se enfoca en sentido de transferencia social.

Ya en el año 2012, Muñoz et al. alertaban sobre la necesidad de formación del profesorado en el ámbito infográfico, realizando un estudio en que la base fundamental era "En la educación superior se constata un renovado interés por el diseño, producción y utilización de recursos multimedia. Pero su complejidad en aspectos técnicos, gráficos o pedagógicos, puede resultar problemática y desanimar a los docentes interesados en crear materiales multimedia" (Muñoz et al., 2012).

Encontramos algunos ejemplos de la infografía aplicada a la docencia y suelen basarse en la facilidad de la transmisión de un mensaje, dado que "la transmisión de información basada en la exposición de infografías puede ayudar a asimilar conocimientos de una manera sencilla y directa, siendo una herramienta docente útil para mejorar los conocimientos" (Olmedo Martín, 2018).

En ocasiones, debido a la plasticidad que plantea la herramienta, podría ser infravalorada, pero debamos tener en cuenta que "la Infografía va más allá de la mera creación de gráficos. Su principal objetivo es convertir lo complejo en sencillo y explicar lo difícil de la forma más clara posible utilizando el lenguaje gráfico. Su materia prima es la información y 
los datos son sintetizados y transformados a códigos visuales para que de un solo vistazo se pueda comprender la realidad que se muestra". (Gamonal, 2013).

Asimismo, como tiene una dimensión transversal, la reflexión forma parte del proceso docente, con lo que hay autores que han valorado este proceso como enriquecedor a nivel global: "la formación de alumnos activos y reflexivos presupone una estrecha unidad dialéctica de la actividad interna y externa en el proceso de enseñanza- aprendizaje, lo que implica no solo determinado desarrollo motivacional e intelectual, sino también de la autoconciencia y de la voluntad y, en fin, de toda la personalidad" (De la Paz-Vizqueira, 2020).

Nuestro convencimiento de que no solo formamos profesionales, sino también personas, se plantea el andamiaje de Bruner (1978) o instructional scaffolding (Delmastro, 2008), entendiendo la docencia como motivadora, basada en competencias transversales del alumnado (Carabal et al., 2017). En este contexto, la reflexión adquiere una importancia fundamental, si pretendemos que el alumnado potencie sus propios talentos durante la docencia universitaria, en la que el profesorado adquiere una tarea fundamental de acompañamiento en su propio autoaprendizaje, que seguirán desarrollando a lo largo de su carrera laboral. Una de las herramientas fundamentales es el debate o diálogo, que ya está integrado en el aula de manera normalizada y que fue estudiado ampliamente por Rosemberg, tratando de darle una visión analítica a los resultados obtenidos con el discurso del alumnado, desde la infancia (Rosemberg, 1999). En ese diálogo, una parte de las ideas básicas son planteadas verbalmente, pero en este caso se presenta una herramienta que no solo sea traducida de manera verbal, sino también gráfica.

Con ello, como hemos observado, la realización de infografías requiere una reflexión que rebasa la adquisición de contenidos, entrando en el terreno transversal, cuyo ámbito de aplicación es múltiple, debido a su naturaleza versátil y a la sociedad basada en la imagen.

\section{Ejemplos desarrollados en el curso 2019-2020}

Los ejemplos que se van a mostrar a continuación, se plantearon a partir de septiembre de 2019, en el momento en que los trabajos final de grado y de Master comenzaban a tomar forma. Desde este primer momento, se empleó la herramienta infográfica como una posibilidad para poder transferir a la sociedad los productos de las investigaciones realizadas por el alumnado en estos trabajos. El alumnado, comprendió que, dada la diversidad social a la que se enfrentaban los resultados de sus trabajos, una manera de unificar la percepción de los mismos, era el empleo de la infografía, por ello aceptaron formar parte de la propuesta infográfica para transferencia social. 
En el caso trabajado, los ejemplos de Navarro y Ojeda sirven para analizar la dimensión didáctica de la infografía en áreas como la conservación preventiva (Imágenes 1 y 2) de patrimonio o la difusión de las investigaciones realizadas sobre las piezas (Imágenes 3 y 4), para ser expuestas al lado de las mismas, ofreciendo información al público en general y a las comunidades a las que pertenecen.

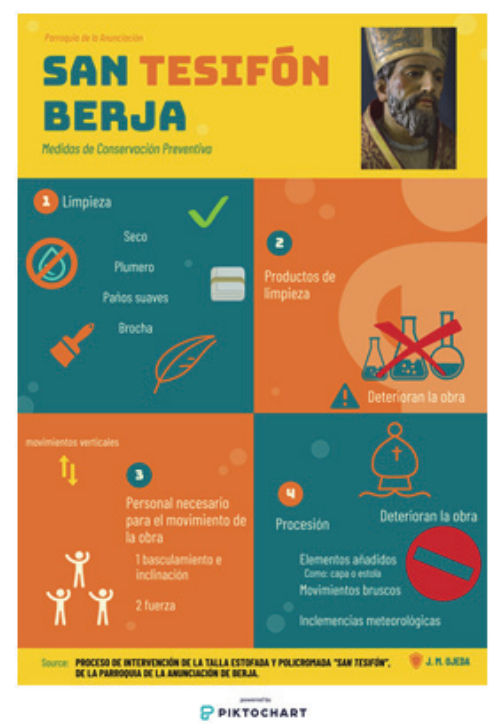

Fig. 1 Infografia referente a la Conservación Preventiva de la imagen de San Tesifón de Berja, tras su restauración. Fuente: Ojeda Salmerón, 2020. 


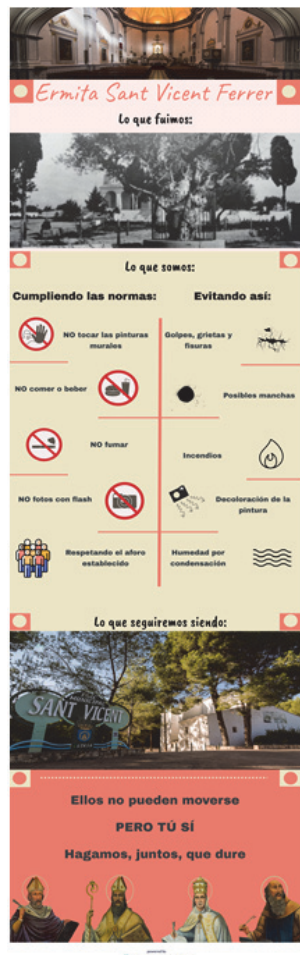

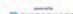
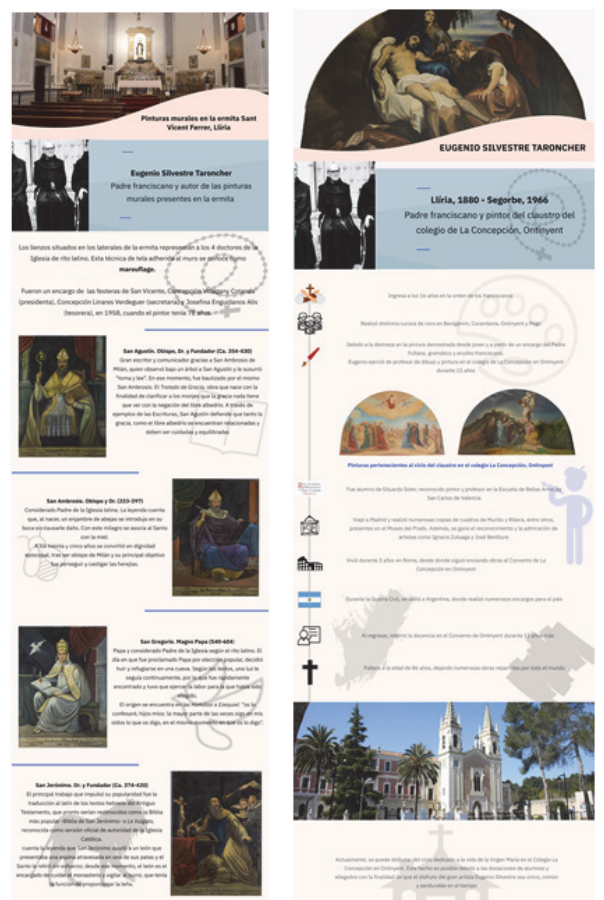

Pentoenenen

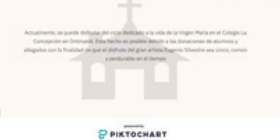

Figs. 2,3 y 4. Infografias referentes a las Pinturas Murales de la Ermita de Sant Vicent Ferrer, Lliria.

Fuente: Navarro Moreno, 2020.

\section{Conclusiones}

Con los ejemplos planteados, se verifica que el empleo de las infografías constituye un elemento facilitador, en el momento en que se pone en marcha la metodología de Aprendizaje-Servicio, estableciéndose una comunicación con la sociedad, a la que se le presta un código interpretativo, adaptado en claves visuales para comprender aspectos técnicos utilizados en el ámbito universitario.

Con ello, el alumnado ha aprehendido los contenidos trabajados en clase, ha ahondado en ellos para extraer los conceptos clave, ha empleado técnicas innovadoras entrelazadas con la creatividad de cada uno dando como resultado un producto creativo, innovador, visual y dinámico, dirigido a la sociedad y cumpliendo así con su función de Aprendizaje-Servicio.

Esta transferencia social de los resultados obtenidos es es el último eslabón que completa el aprendizaje, dimensiona su investigación en el contexto comunitario y lo integra en la cotidianidad. 


\section{Agradecimientos}

Al equipo del EICE titulado El proceso de Enseñanza y Aprendizaje Fuera de las Aulas de la Facultad de Bellas Artes: Baños de Realidad, del Instituto de Ciencias de la Educación de la Universitat Politècnica de València.

Al alumnado que ha generado documentos infográficos, que ha cedido para el siguiente artículo, José Manuel Ojeda Salmerón, alumno del Máster en Conservación y Restauración de Bienes Culturales, que ha realizado infografías en el apartado social de su TFM y Valeria Navarro Moreno, alumna de Grado en Conservación y Restauración de Bienes Culturales, ambos de la Universitat Politècnica de València.

\section{Referencias}

Bruner, J. (1978). The role of dialogue in language acquisition' In A. Sinclair, R., J. Jarvelle, and W. J. M. Levelt (Eds.) The Child's Concept Of Language. New York: Springer-Verlag.

Carabal-Montagud, M.A., Santamarina-Campos, V., De Miguel-Molina, M., De Miguel-Molina, M.B., (2017). "Uso del Phubbing como estrategia de aprendizaje" UPV. En Comunica2. Valencia: Editorial UPV. Pp 107-121. ISBN 978-84-945855-3-1. Disponible en https://datos.comunica2.webs.upv.es/uploads/2018/02/Actas-7Comunica2-2017.pdf [Consulta: 3 de marzo de 2020]

Carril, P. C. M., Abeledo, E. J. F., \& Sanmamed, M. G. (2012). Necesidades formativas del profesorado universitario en infografía y multimedia. Revista de Investigación Educativa, 30(2), 303-321.

De la Paz-Vizqueira, L. M. (2020). El contenido esencial para infografía en el proceso de enseñanza de las Telecomunicaciones. Maestro y Sociedad, 211-224.

Delmastro, A. L. (2008). EL ANDAMIAJE DOCENTE EN EL DESARROLLO DE LA LECTURA Y LA ESCRITURA EN LENGUA EXTRANJERA. Paradígma, 29 (1). Disponible en: https://web.b.ebscohost.com/abstract?direct=true \&profile=ehost\&scope $=$ site $\&$ authtype $=$ crawler $\&$ $\mathrm{jrnl}=10112251 \& \mathrm{AN}=36157487 \& \mathrm{~h}=\mathrm{JV}$ cxex6w\%2bkkYLhCBASZY $1 \mathrm{t} \%$ \% $\mathrm{fMXnNJv} \% 2 \mathrm{f} 9 \mathrm{~S} 3 \mathrm{mE}$ YDO5n7F0NKViGQ3ujc7luX8hjnH9loDj16cQHTpYkZyxaqJjyw\%3d\%3d\&crl=c\&resultNs=Ad minWebAuth\&resultLocal=ErrCrlNotAuth\&crlhashurl=login.aspx $\% 3 \mathrm{fdirect} \% 3 \mathrm{dtrue} \% 26$ profile \%3dehost $\% 26$ scope $\% 3$ dsite $\% 26$ authtype $\% 3$ dcrawler $\% 26 j$ rnl $\% 3 \mathrm{~d} 10112251 \% 26 \mathrm{AN} \% 3 \mathrm{~d} 3615748$ I [Consulta: 9 de junio de 2020].

Gamonal A., R. (2013). Infografía: etapas históricas y desarrollo de la gráfica informativa. Historia y Comunicación Social, 18 ( $\mathrm{N}^{\mathrm{o}}$ Especial).

Navarro Moreno, V. (2020). Estudio técnico y propuesta de intervención de los conjuntos murales ubicados en la ermita de Sant Vicent Ferrer, Llíria (València). Trabajo Final de Grado en Conservación y Restauración de Bienes Culturales. Universitat Politècnica de València. Inédito. 
Ojeda Samerón, J.M. (2020). Proceso de intervención de la talla estofada y policromada "San Tesifón", de la Parroquia de la Anunciación de Berja. Descripción del estado de conservación, propuesta de intervención y fases de su restauración. Trabajo Final de Máster en Conservación y Restauración de Bienes Culturales. Universitat Politècnica de València. Inédito.

Olmedo Martín, E. (2018). Las infografías como herramienta docente y de impacto informativo. Disponible en https://uvadoc.uva.es/bitstream/handle/10324/30220/TFG-MM1102.pdf? sequence=1\&isAllowed=y [Consulta: 20 de junio de 2020].

Rosemberg, C. R. (1999). La conversación en el aula: el discurso como andamiaje. Disponible en http://dspace5.filo.uba.ar/handle/filodigital/6607 [Consulta: 15 de junio de 2020]. 